\title{
Thyroid Dysfunction among Patients with Diabetes Mellitus in Kathmandu
}

\author{
Khema Raj Bhusal, ${ }^{1}$ Rabindra Simkhada, ${ }^{2}$ Pratap Pokhrel ${ }^{1}$ \\ ${ }^{1}$ Kantipur General Hospital and Kantipur Dental College, Kathmandu, ${ }^{2}$ Shahid Gangalal National Heart Centre, \\ Kathmandu, Nepal.
}

\begin{abstract}
Background: This study was conducted with the objective of studying thyroid dysfunction in patients with diabetes mellitus. Materials and Methods: A total 100 patients consisting of 40 males and 60 females diagnosed as diabetes were included in the study. Laboratory values of different thyroid parameters were taken. Results: Among the participants $60 \%$ were female and $40 \%$ were male. Age ranged from 17 to 88 years with mean being $55.73 \pm 1.62$ years. Presence of thyroid dysfunction was found in $35 \%$ of the cases. Subclinical hypothyroidism was found in $20 \%$ of participants, frank hypothyroidism in $10 \%$, subclinical hyperthyroidism in 3\% and frank hyperthyroidism in 2\%. Conclusions: This study showed the high prevalence of thyroid dysfunction in patients with diabetes mellitus. Early testing for thyroid function is very useful to detect dysthyroidism in all diabetic patients.
\end{abstract}

Keywords: diabetes; thyroid dysfunction; subclinical hypothyroidism.

\section{INTRODUCTION}

Disorders of the thyroid gland and carbohydrate metabolism such as diabetes mellitus (DM) are among the most common endocrine disorders. ${ }^{1}$ Elevated levels of free circulating thyroid hormones (hyperthyroidism) produce hyperglycaemia by causing polyphagia, enhancing glucose absorption from the gastro-intestinal tract, accelerating insulin degradation and stimulating glycogenolysis. By opposite action, reduced levels of the hormones in hypothyroidism may cause hypoglycaemia. ${ }^{2}$ Autoimmunity, in which circulating antibodies exist to numerous body tissue components destroy such tissues was stated to be the underlying mechanism behind the increased prevalence of thyroid disorders in type 1A diabetes. ${ }^{3}$ However in type 2 diabetics also, autoimmune thyroid diseases are known to be highly prevalent. ${ }^{4}$

The association between all forms of diabetes and thyroid dysfunction has been studied in different parts of the world with variable results since the first studies published in 1979. ${ }^{5}$ Thyroid Disease Prevalence study involving 25,862 participants attending a state health fair, $9.5 \%$ of the studied population were found to have an elevated TSH, while $2.2 \%$ had a low TSH. $^{6}$ In the NHANES III study, a survey of 17,353 subjects representing the
US population, thyroid dysfunction was found in higher frequency with advancing age and a higher prevalence of thyroid disease is found in women compared to men and in diabetic subjects compared to nondiabetic. ${ }^{7}$ High $(29 \%)$ prevalence of thyroid dysfunction is shown in South Asian diabetics also in a study done in Bangalore, India. ${ }^{8}$ Diabetes mellitus (DM) is a growing problem in Nepal. The prevalence of thyroid dysfunction is also not uncommon. We aimed to see the association of thyroid dysfunction with diabetes mellitus which will help us to manage our patients more precisely.

\section{MATERIALS AND METHODS}

This is an cross-sectional study done in Green City Hospital from January to March 2018. One hundred (100) patients with diabetes mellitus that attended the out-patient clinic were included in the study randomly. Written informed consent for the study was obtained from all of the participants and approval was taken from the hospital. Only adult participants with age 16 years and above were included. Diabetes patients irrespective of taking antidiabetic medication and either controlled or uncontrolled glycemic status were included. The patients with known thyroid dysfunction were excluded. Patients with gestational diabetes mellitus, pancreatitis, those using corticosteroid, radioiodine

Correspondence: Dr. Khema Raj Bhusal, Kantipur General Hospital and Kantipur Dental College, Kathmandu, Nepal. Email: khemrbhusal@yahoo.com. Phone: 977- 9841312739. ORCID: https://orcid.org/0000-0003-0813-2019 DOI: $10.3126 /$ jcmsn.v14i4.20243. Article received: 2018-06-13. Article accepted: 2018-12-19. 
and those having proven thyroid disorder and on treatment for thyroid disorder were excluded. Similarly participants who did not give consent were excluded.

All participants underwent a clinical and laboratory evaluation. The demographic data were obtained from a survey. The following variables were assessed: gender, age (years), BMI (weight and height). Blood samples were obtained after a 12 hour overnight fast for biochemical analysis: fasting and 2 hour-postprandial glycemia,triiodothyronine(FT3), free freethyroxine (FT4) and thyrotropin (TSH).

Fasting and post prandial blood sugar were tested with Spectrophotometer via (Glucose oxidase/ peroxidase method) GOD/POD method. Test for T3, T4 and TSH were done via chemiluminescence immunoassay (CLIA).

According to American Diabetic Association Position Statement 2010, Diabetes mellitus type 2 was defined with fasting blood glucose (FBS) $\geq 126$ $\mathrm{mg} / \mathrm{dl}$ or two-hour postprandial blood glucose (PPBS) $\geq 200 \mathrm{mg} / \mathrm{dl}$ or taking antidiabetic drugs. Thyroid dysfunction was defined as clinical or overt hypothyroidism with $\mathrm{FT} 4<0.91 \mathrm{ng} / \mathrm{dl}$ and $\mathrm{TSH}>5.06 \mathrm{mU} / \mathrm{L}$, clinical or overt hyperthyroidism with FT4 $>1.55 \mathrm{ng} / \mathrm{dl}$ and $\mathrm{TSH}<0.32 \mathrm{mU} / \mathrm{L}$, subclinical hypothyroidism with $\mathrm{TSH}>5.06 \mathrm{mU} / \mathrm{L}$ and $0.91 \leq \mathrm{FT} 4 \leq 1.55$,subclinical hyperthyroidism with $\mathrm{TSH}<0.32 \mathrm{mU} / \mathrm{L}$ and $0.91 \leq \mathrm{FT} 4 \leq 1.55 \mathrm{ng} / \mathrm{dl} .{ }^{9}$

Data were entered in the Statistical Package for the Social Sciences (SPSS) version 16 for windows and analysed. Categorical variables were described as frequency (percentage), mean \pm standard deviation were used for continuous parameters. Analysis of association of TSH, T3, T4, FBS and PPBS in different age, sex, duration of diabetes was done by using Analysis of Variation (ANOVA) test. For all analyses p-value of $<0.05$ was considered statistically significant.

\section{RESULTS}

Among the participants $60 \%$ were female and $40 \%$ were male. Age ranged from 17 to 88 years with mean being $55.73 \pm 1.62$ years. Most of the participants (48\%) were of 41-60 years, $33 \%$ were more than 60 years and $19 \%$ were less than 40 years (Table 1). Mean BMI was in overweight category $(27.66 \pm 5.67 \mathrm{~kg} / \mathrm{m} 2)$. Presence of thyroid dysfunction was found in $35 \%$ of the total cases. Subclinical hypothyroidism was found in $20 \%$ of

\begin{tabular}{|c|c|}
\hline Duration of DM & No. of patients \\
\hline$<5$ years & 29 \\
\hline$>5$ & 71 \\
\hline Total & 100 \\
\hline ( $p$ value) & $\mathrm{p}=0.098$ \\
\hline
\end{tabular}

participants, overt hypothyroidism in $10 \%$, subclinical hyperthyroidism in $3 \%$ and overt hyperthyroidism in $2 \%$. In this study $38.33 \%$ female (23 out of 60 ) and $30 \%$ male (12 out of 40 ) has thyroid dysfunction (Table 2).

\begin{tabular}{|lcc|}
\hline \multicolumn{3}{|l|}{$\begin{array}{l}\text { Table } \\
\text { ables using }\end{array}$ one way ANOVA (p values shown). } \\
\hline Variables & Age (in years) & Sex (male vs female) \\
FBS & 0.54 & 0.24 \\
PPBS & 0.12 & 0.87 \\
T3 & 0.21 & 0.259 \\
T4 & 0.26 & 0.33 \\
TSH & 0.002 & 0.81 \\
\hline
\end{tabular}

Thyroid dysfunction was found maximum (39.58\%) in age group of 41-60 years followed by $>60$ years and least in $\leq 40$ years.

Mean FBS was 134.32, Mean PPBS was 183.87, mean TSH was 5.38 microUI $/ \mathrm{ml}$, and mean T4 was $1.2 \mathrm{ng} / \mathrm{dl}$, Mean T3 was $2.76 \mathrm{pg} / \mathrm{ml}$. Out of 100 diabetics in our study, $20 \%$ were new onset diabetes, $5 \%$ were old diabetes not under treatment and $75 \%$ were diabetes under treatment. 30 people were in the duration of $0-5$ years and 34 were 6-10 years and the remaining 36 had more than 10 years duration of diabetes. Increase in thyroid dysfunction had no significance association with increased duration of diabetes in this study $(\mathrm{p}=0.58)$.

Thyroid dysfunction indicated by increasing TSH level was significantly associated with increasing age $(p=0.002)$. But no significant association of increasing age or either sex was found with FBS, PPBS, T3 or T4.

\section{DISCUSSION}

Out of 100 patients taken female were $60 \%$, and male were $40 \%$ and mean BMI was $27.66 \pm 5.67 \mathrm{~kg} /$ $\mathrm{m} 2)$. This study demonstrated a $35 \%$ prevalence of Thyroid Dysfunction. This is comparable to $29 \%$ prevalence of thyroid dysfunction among diabetics in a study done in India. ${ }^{8}$ Pasupathi et al in a study found that prevalence of thyroid dysfunction was $45 \%$ in type 2 diabetic population where hypothyroidism was present in $28 \%{ }^{10}$ This is 
comparable to our study where hypothyroidism is found in $30 \%$.

Out of total $35 \%$ thyroid dysfunction cases of our study, subclinical hypothyroidism is found in $20 \%$ (9 male and 11 female) of participants, frank hypothyroidism in $10 \%$ ( 1 male and 9 female), subclinical hyperthyroidism in $3 \%$ (1 male and 2 female) and frank hyperthyroidism in $2 \%$ ( 1 male and 1 female). This is comparable to $31 \%$ of overall thyroid dysfunction in a study done in Cairo, Egypt where $25 \%$ had subclinical hypothyroidism, 3.5\% had clinical hypothyroidism and $2.5 \%$ had clinical hyperthyroidism and no cases of subclinical hyperthyroidism. ${ }^{11}$

In our study $38.33 \%$ female (23out of 60 ) and $30 \%$ male (12 out of 40) has thyroid dysfunction. Laloo et al., in their study having $31.2 \%$ thyroid dysfunction also showed more prevalence of thyroid dysfunction in female similar to our study. In this study, $16.3 \%$ had subclinical hypothyroidism (10 males and 23 females), 23 (11.4\%) had overt hypothyroidism (6 males and 17 females), 4 (2\%) had subclinical hyperthyroidism and $3(1.5 \%)$ were overt hyperthyroidism cases. ${ }^{12}$

So, the prevalence of thyroid dysfunction and the different categories of thyroid dysfunction among diabetics in our participants were comparable to the study done previously in various other setting.

\section{Limitations}

The main limitation of our study is the small number of population taken. As the present study was hospital based and not a cross sectional population study, the finding of this study may not be truly representative to the general population at large. This was a single centre study, we encourage a larger study including more variables in future.

\section{CONCLUSIONS}

This study showed a high prevalence of thyroid dysfunction in diabetic people. This indicates that screening for thyroid disease in diabetic people should be routinely performed. The classical risk factors like hypertension and dyslipidemia, arising from an undiagnosed thyroid dysfunction may lead to increased mortality and cardiovascular events in diabetic population. Early finding of thyroid dysfunction is of paramount importance in decreasing morbidity and mortality. This will certainly help to increase the quality of life of people with diabetes mellitus by reducing complication.

\section{REFERENCES}

1. Yavorski RT, Wong RK, Maydonovitch C, Battin LS, Furnia A, Amundson DE. Analysis of 3,294 cases of upper gastrointestinal bleeding in military medical facilities. Am J Gastroenterol. 1995; 90:568-73.

2. Duntas LH, Orgiazzi J, Brabant G. The interface between thyroid and diabetes mellitus. ClinEndocrinol. 2011; 75(1):1-9.

3. Loeb JN. Metabolic changes in thyrotoxicosis. Werner and Ingbar's The thyroid.1996; 687-93.

4. Hawa MI, Picardi A, Costanza F , D'avola D, Berreta G, Anguissola N, et al. Frequency of diabetes and thyroid auto antibodies in patients with auto immune endocrine disease from Cameroon. Clinical immunology. 2010; 18: 229-32.

5. Wu P. Thyroid Disease and Diabetes. Clinical Diabetes.2000; 18 (1): 1-4.

6. Feely J, Isles TE. Screening for thyroid dysfunction in diabetics. Br Med J. 1979;1:1678.

7. Canaris GJ, Manowitz NR, Mayor G, E. C. Ridgway. The colorado thyroid disease prevalence study. Archives of Internal Medicine. 2000; 160 (4):
526-34.

8. Hollowell JG, Staehling NW, Flanders WD. Serum TSH, T4, and thyroid antibodies in the United States population (1988 to 1994). National Health and Nutrition Examination Survey (NHANES III). Journal of Clinical Endocrinology and Metabolism. 2002; 87 (2): 489-99.

9. Ravi-Shankar SN, Champakamalini, Venkatesh. A prospective study of thyroid - dysfunction in patients with Type 2 diabetes in general population. IMedPub Journals. 2013; 5: 1-2.

10. Pasupathi P, Bakthavathsalam G, Saravanan G, Sundaramoorthi R. Screening for thyroid dysfunction in the diabetic/ non-diabetic population. Thyroid Science.2008; 3(8):CLS1-6.

11. Elmenshawi IM, Alotaibi SS, Alazmi AS, Alazmi AM, Alruwaili FR. Prevalence of Thyroid Dysfunction in Diabetic Patients. $J$ Diabetes MetabDisord Control. 2017; 4(2): 00106.

12. Laloo D, Salam R. Thyroid dysfunction in type 2 diabetes mellitus: A retrospective study. Indian J EndocrinolMetab. 2012 December; 16 (Suppl 2): S334-S35.

Citation: Khema Raj Bhusal KR, Simkhada R, Pokhrel P. Thyroid Dysfunction among Patients with Diabetes Mellitus in Kathmandu. JCMS Nepal. 2018;14(4):206-8. 